\title{
T lymphocyte response against pancreatic beta cell antigens in fulminant Type 1 diabetes
}

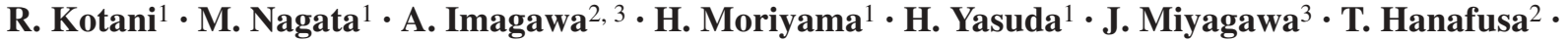 \\ K. Yokono ${ }^{1}$ \\ ${ }^{1}$ Division of Internal and Geriatric Medicine, Department of Development and Aging, \\ Kobe University Graduate School of Medicine, Chuo-ku, Kobe, Japan \\ 2 First Department of Internal Medicine, Osaka Medical College, Japan \\ ${ }^{3}$ Department of Internal Medicine and Molecular Science, Graduate School of Medicine, Osaka University, Japan
}

\section{Abstract}

Aims/hypothesis. Fulminant Type 1 diabetes is a novel subtype of Type 1 diabetes that involves the abrupt onset of insulin-deficient hyperglycaemia. This subtype appears to be non-autoimmune because of the absence of diabetes-related autoantibodies in the serum, and of insulitis in pancreatic biopsy specimens. The pathogenesis of the disease is still unknown. In this study, we investigated whether $\mathrm{T}$ cell autoimmune responses are involved in fulminant Type 1 diabetes.

Methods. Cellular immune responses to beta cell autoantigens were studied by enzyme-linked immunospot (ELISPOT) assay in 13 fulminant Type 1 diabetic patients and 49 autoantibody-positive autoimmune Type 1 diabetic patients. Results were compared with those of 18 Type 2 diabetic patients, six second- ary diabetic patients (diabetes due to chronic pancreatitis) and 35 healthy controls.

Results. Nine of 13 (69.2\%) GAD-reactive Th1 cells, and three of 12 (25\%) insulin-B9-23-reactive Th1 cells were identified in fulminant Type 1 diabetic patients by ELISPOT, as in autoantibody-positive Type 1 diabetic patients. Four fulminant Type 1 diabetic patients possessed the highly diabetes-resistant allele DR2, three of whom had GAD-reactive Th1 cells in the periphery. Conclusions/interpretation. Peripheral immune reaction was observed in $69.2 \%$ of fulminant Type 1 diabetic patients, indicating that autoreactive $\mathrm{T}$ cells might contribute, at least in part, to the development of fulminant Type 1 diabetes.

Keywords Autoimmune $\cdot$ ELISPOT $\cdot$ Fulminant . $\mathrm{T}$ cell $\cdot$ Type 1 diabetes
Received: 15 December 2003 / Accepted: 17 April 2004 Published online: 9 July 2004

C) Springer-Verlag 2004

M. Nagata ( $)$

Division of Internal and Geriatric Medicine,

Department of Development and Aging,

Kobe University Graduate School of Medicine,

7-5-1 Kusunoki-cho, Chuo-ku, Kobe 650-0017, Japan

E-mail: nagata@med.kobe-u.ac.jp

Tel.: +81-78-3825901

Abbreviations: ELISPOT, enzyme-linked immunospot · IA-2, tyrosine phosphatase-like protein - ICA, islet cell antibodies $\cdot \mathrm{mAb}$, monoclonal antibody $\cdot \mathrm{PBMC}$, peripheral blood mononuclear cells · PHA, phytohaemagglutinin .

PPD, purified protein derivative

\section{Introduction}

According to the new classification for diabetes mellitus introduced by the American Diabetes Association, Type 1 diabetes can be subclassified into Type 1A (autoimmune) and Type 1B (idiopathic) diabetes [1, 2]. However, the cause of Type $1 \mathrm{~B}$ diabetes has not yet been identified. Recently, a novel subtype of Type 1B diabetes has been recorded and referred to as fulminant Type 1 diabetes, characterised by a remarkably abrupt onset with no insulitis or diabetes-related antibodies. Studies of fulminant Type 1 diabetes have shown a high frequency of serum pancreatic enzyme elevation, as well as the infiltration of $\mathrm{T}$ cells in exocrine tissue during pancreatic biopsy $[3,4]$. The clinical and immunohistochemical features of this subtype of Type 1 diabetes contrast with those of Type $1 \mathrm{~A}$ diabetes, which involves autoimmune destruction of pancreatic beta cells. 
The incidence of fulminant Type 1 diabetes is not likely to be low, as more than $20 \%$ of ketosis-onset Type 1 diabetic cases in Japan have consistent features [5]. The involvement of immunological mechanisms in beta cell destruction has been discussed. Case reports have described pancreatic insulitis in an autopsy case, and later detection of antibodies after the onset of fulminant Type 1 diabetes $[6,7]$. On the other hand, the involvement of viral infections has also been suggested because of the abrupt onset [8, 9]. However, the common aetiology of fulminant Type 1 diabetes has not yet been clarified.

We have recently reported that an immunoglobulinfree ELISPOT assay can detect $\mathrm{T}$ cell reactivity to islet cell antigens in $66.7 \%$ of Type 1 diabetic patients, with good reproducibility [10]. In the previous report, six of seven Type 1 diabetic patients with no diabetes-related antibodies also had GAD-reactive T-helper-1 cells [10]. To investigate whether $\mathrm{T}$ cell autoimmune responses are involved in fulminant Type 1 diabetes, we evaluated the presence of islet cell antigen-reactive $\mathrm{T}$ cells using an ELISPOT assay in fulminant Type 1 diabetic patients.

\section{Subjects, materials and methods}

Subjects. We studied 13 Japanese patients with fulminant Type 1 diabetes (four males aged 38-45 years and nine females aged $17-47$ years; mean \pm SD, $31.3 \pm 10.7$ ). Fulminant Type 1 diabetes was diagnosed according to the following inclusion criteria provisionally proposed by the Committee of Japan Diabetes Society: (i) abrupt onset of overt diabetes with ketoacidosis; (ii) exhaustion of insulin secretion (urinary C-peptide excretion $<3.31 \mu \mathrm{mol} / \mathrm{day}$; fasting serum concentration of C-peptide $<0.1 \mu \mathrm{mol} / \mathrm{l}$; serum concentration of C-peptide after glucagon injection $<0.17 \mu \mathrm{mol} / \mathrm{l}$; or postprandial serum concentration of C-peptide $<0.17 \mu \mathrm{mol} / \mathrm{l}$ ); and (iii) $\mathrm{HbA}_{1} \mathrm{c}$ at onset $<8.5 \%$. The clinical characteristics of the 13 fulminant Type 1 diabetic patients are summarised in Table 1. For comparison, we also stud- ied 49 patients with autoimmune Type 1 diabetes (20 males aged 15-65 years and 29 females aged 5-75 years; mean \pm SD, $33.8 \pm 15.7)$ who were all autoantibody-positive. The duration of diabetes in autoimmune and fulminant Type 1 diabetic patients was 0.1-32 years (mean $\pm \mathrm{SD}, 7.9 \pm 9.3$ ) and $0.1-11.3$ years $(3.1 \pm 4.2)$ respectively. In addition, 35 healthy subjects ( 19 males and 16 females aged $23-44$ years; mean \pm SD, 33.4 \pm 5.7 ) and 18 Type 2 diabetic patients (6 males and 12 females aged 31-80 years, 55.3 \pm 16.7 ) were studied as controls, and six pancreatic diabetic patients (diabetes due to chronic pancreatitis; 5 males aged 33-67 years and 1 female aged 45 years; mean \pm SD, $51.2 \pm 11.7)$ were studied as negative controls. Serum antibodies to GAD were measured using a radioimmunoassay kit (GADAb Cosmic; Cosmic Corporation, Tokyo, Japan). The specificity and sensitivity of the kit were both reported to be $100 \%$ in the second and third GAD proficiency test results evaluations (University of Florida, Gainesville, Fla., USA). GAD antibodies for some patients who had a long duration of diabetes were determined using another radioimmunoassay kit (Rip-GAD; Hoechst Japan, Tokyo, Japan), of which the specificity and sensitivity were $100 \%$ and $89.5 \%$, respectively, in the Second International GAD-Ab Workshop. A value greater than $5 \mathrm{U} / \mathrm{ml}$ (Rip-GAD) or 1.5 U/ml (GAD-Ab Cosmic) was considered positive. Tyrosine phosphatase-like protein (IA-2) antibody was measured using an IA-2 immunoprecipitation assay kit (Cosmic). The normal range of IA-2 antibodies determined for healthy Japanese blood donors is $<0.4 \mathrm{U} / \mathrm{ml}$. The measurement parameters for IA-2 antibodies using an immunoprecipitation assay have previously been reported by Masuda et al. [11]. Islet cell antibodies (ICA) were measured by indirect immunofluorescence, with an abnormal value defined as more than 5 Juvenile Diabetes Foundation units [12]. All subjects gave their written informed consent to participate in the study, which was conducted according to the ethical guidelines of Kobe University Medical Hospital.

Antigens. Purified recombinant human GAD65 expressed in yeast (Saccharomyces cerevisiae) was obtained from RSR (Cardiff, UK). The properties of this GAD65 preparation, including its reactivity with GAD autoantibodies (known to react with conformational epitopes on the GAD65 molecule), have previously been described in detail $[13,14]$. The N-terminal amino acids 2-45 were deleted from the preparation because $\mathrm{N}$-terminally modified GAD65 was stable in solution. The purity of GAD65

Table 1. Profile of fulminant Type 1 diabetic patients and HLA typing

\begin{tabular}{|c|c|c|c|c|c|c|c|c|c|}
\hline \multirow[t]{2}{*}{ Subject } & \multirow[t]{2}{*}{ Sex } & \multirow{2}{*}{$\begin{array}{l}\text { Age } \\
\text { (years) }\end{array}$} & \multirow{2}{*}{$\begin{array}{l}\mathrm{HbA}_{1} \mathrm{c} \text { at } \\
\text { onset }(\%)\end{array}$} & \multirow{2}{*}{$\begin{array}{l}\text { Duration } \\
\text { of diabetes } \\
\text { (years) }^{\mathrm{a}}\end{array}$} & \multicolumn{3}{|c|}{ Autoantibodies at onset } & \multirow{2}{*}{$\begin{array}{l}\text { F-CPR } \\
(\mu \mathrm{mol} / 1)\end{array}$} & \multirow{2}{*}{$\begin{array}{l}\text { HLA typing } \\
\text { DR }\end{array}$} \\
\hline & & & & & GAD (U/ml) & IA-2 (U/ml) & ICA (JDFU) & & \\
\hline 2 & M & 39 & 6.0 & 0.1 & $<1.5$ & $<0.4$ & nd & 0.07 & $1 / 4$ \\
\hline 3 & $\mathrm{~F}$ & 47 & 5.5 & 10.5 & $<4$ & $<0.4$ & $<5$ & $<0.03$ & $2 / 6$ \\
\hline 4 & $\mathrm{~F}$ & 17 & 5.4 & 0.9 & $<1.5$ & $<0.4$ & $<5$ & 0.07 & $2 / 4$ \\
\hline $7 \mathrm{~b}$ & $\mathrm{~F}$ & 20 & 6.8 & 1.5 & $<1.3$ & $<0.4$ & $<5$ & 0.07 & $2 / 4$ \\
\hline 8 & $\mathrm{~F}$ & 38 & 6.4 & 0.2 & $<1.5$ & nd & $<5$ & 0.07 & nd \\
\hline $9^{b}$ & M & 45 & 6.7 & 4.0 & $<1.5$ & $<0.4$ & $<5$ & 0.07 & $1 / 4$ \\
\hline 10 & $\mathrm{~F}$ & 29 & nd & 9.0 & $<4$ & $<0.4$ & $<5$ & 0.07 & $4 / 8$ \\
\hline 11 & $\mathrm{~F}$ & 38 & 7.6 & 0.7 & $<1.3$ & nd & nd & 0.07 & $4 /-$ \\
\hline $12^{b}$ & $\mathrm{~F}$ & 23 & 5.4 & 0.9 & $<1.3$ & nd & nd & 0.07 & $4 /-$ \\
\hline
\end{tabular}

a Duration refers to the period from the diagnosis of diabetes to the date of ELISPOT assay; ${ }^{\mathrm{b}}$ patients who underwent pancreas biopsy; nd, not determined 
was $>95 \%$ and the endotoxin content of $10 \mathrm{mg}$ GAD65 was very low (0.035 endotoxin units). Insulin B9-23 peptide was kindly provided by Dr G. Eisenbarth (Barbara Davis Center for Childhood Diabetes, Denver, Colo., USA). It was synthesised by solidphase strategies on an automated multiple peptide synthesiser, and subsequently purified by reverse-phase high-pressure liquid chromatography by SynPep (Dublin, Calif., USA). The purity of the insulin B9-23 peptide was $>95 \%$. Phytohaemagglutinin (PHA) was obtained from Wako Chemicals (Osaka, Japan), and purified protein derivative (PPD) of mycobacterium tuberculosis was supplied by BCG Japan (Tokyo, Japan).

Pancreatic biopsy and immunohistochemistry. Pancreatic biopsies were performed in three of 12 patients within 5 months of the onset of diabetes, as reported previously [15]. Patients were under local anaesthesia, and a standard laparoscopic technique was used (Olympus, Tokyo, Japan). After inspection of the pancreas, biopsy forceps (Olympus) were inserted into the peritoneal cavity, and 1-2 match-head-sized pancreatic specimens were taken. Tissue was snap-frozen and 5 - $\mu$ m-thick sections were cut on a cryostat for haematoxylin-eosin staining and immunohistochemical study. Double immunofluorescence was employed using anti-human T lymphocyte CD3 (3T-4B5; Dakopatts, Glostrup, Denmark), B lymphocyte (L26; Dakopatts), macrophage (EBM11; Dakopatts), and guinea pig anti-insulin (Dakopatts) or rabbit anti-glucagon antibodies (kindly provided by Dr Iwasa, Takeda Chemical Industries, Osaka, Japan). This protocol was approved by the ethics committee of Osaka University Hospital, and written informed consent was obtained from each patient.

PBMC preparation. Heparinised freshly-drawn blood from each subject was assayed within 6 hours. Peripheral blood mononuclear cells (PBMC) were isolated by Ficoll-Paque density gradient centrifugation (Pharmacia Biotech, Uppsala, Sweden). Per well, 200,000 $\left(2 \times 10^{5}\right)$ PBMC were cultured in nitro-cellulose-bottomed 96-well microtitre plates (Millititer; Millipore, Bedford, Mass., USA) at $37{ }^{\circ} \mathrm{C}$ with $5 \% \mathrm{CO}_{2}$, in $200 \mu \mathrm{l}$ of RPMI 1640 with $2 \mathrm{mmol} / \mathrm{l}$ L-glutamine, supplemented with $10 \%$ human type $\mathrm{AB}$ serum, $5 \times 10^{-5} \mathrm{~mol} / \mathrm{l} 2-\mathrm{ME}$, $50 \mathrm{U} / \mathrm{ml}$ penicillin and $50 \mu \mathrm{g} / \mathrm{ml}$ streptomycin (Flow Laboratories, McLean, Va., USA). The human type AB serum was filtered through Cellulose Easter Membrane (Spectrum Medical Industries, Houston, Tex., USA) to remove substances of over $100,000 \mathrm{M}_{\mathrm{r}}$, including immunoglobulins, which were present thereafter at less than $2 \mu \mathrm{g} / \mathrm{ml}$ total $\mathrm{IgG}$.

ELISPOT assay. The ELISPOT assay was performed as previously described [10]. In brief, nitro-cellulose-bottomed 96-well microtitre plates were coated with $15 \mu \mathrm{g} / \mathrm{ml}$ of mouse antihuman IFN- $\gamma$ monoclonal antibody (mAb; 1-DIK; Mabtech, Stockholm, Sweden) or mouse anti-human IL-4 mAb (IL-4-I; Mabtech AB) in sterile coating buffer $(0.1 \mathrm{~mol} / \mathrm{l}$ carbonatebicarbonate buffer, $\mathrm{pH} 9.6$ ) overnight at $4{ }^{\circ} \mathrm{C}$. Unbound antibodies were removed by washing six times with sterile PBS. Aliquots of $2 \times 10^{5}$ PBMC per well were incubated in $\mathrm{mAb}$ coated plates with the antigens/stimulators as follows for $40 \mathrm{~h}$ : $10 \mu \mathrm{g} / \mathrm{ml}$ GAD65, $10 \mu \mathrm{g} / \mathrm{ml}$ insulin B9-23, $1 \mu \mathrm{g} / \mathrm{ml}$ PPD, and $10 \mu \mathrm{g} / \mathrm{ml}$ PHA. After washing, $1 \mu \mathrm{g} / \mathrm{ml}$ of biotin-conjugated anti-cytokine mAb (7-B6-1 for IFN- $\gamma$ and IL4-II for IL-4) was added to each well and incubated for $3 \mathrm{~h}$ at room temperature, followed by streptavidin conjugated with alkaline phosphatase for $1 \mathrm{~h}$. Finally, BCIP/NBT substrate solution (Bio-Rad Laboratories, Richmond, Calif., USA) was added and incubated until a colour change was noted in the wells (15-25 min). Spots were counted using an NIH imager with a CCD camera, and data were expressed as means of triplicate determinations for each antigen and lymphocyte concentration.
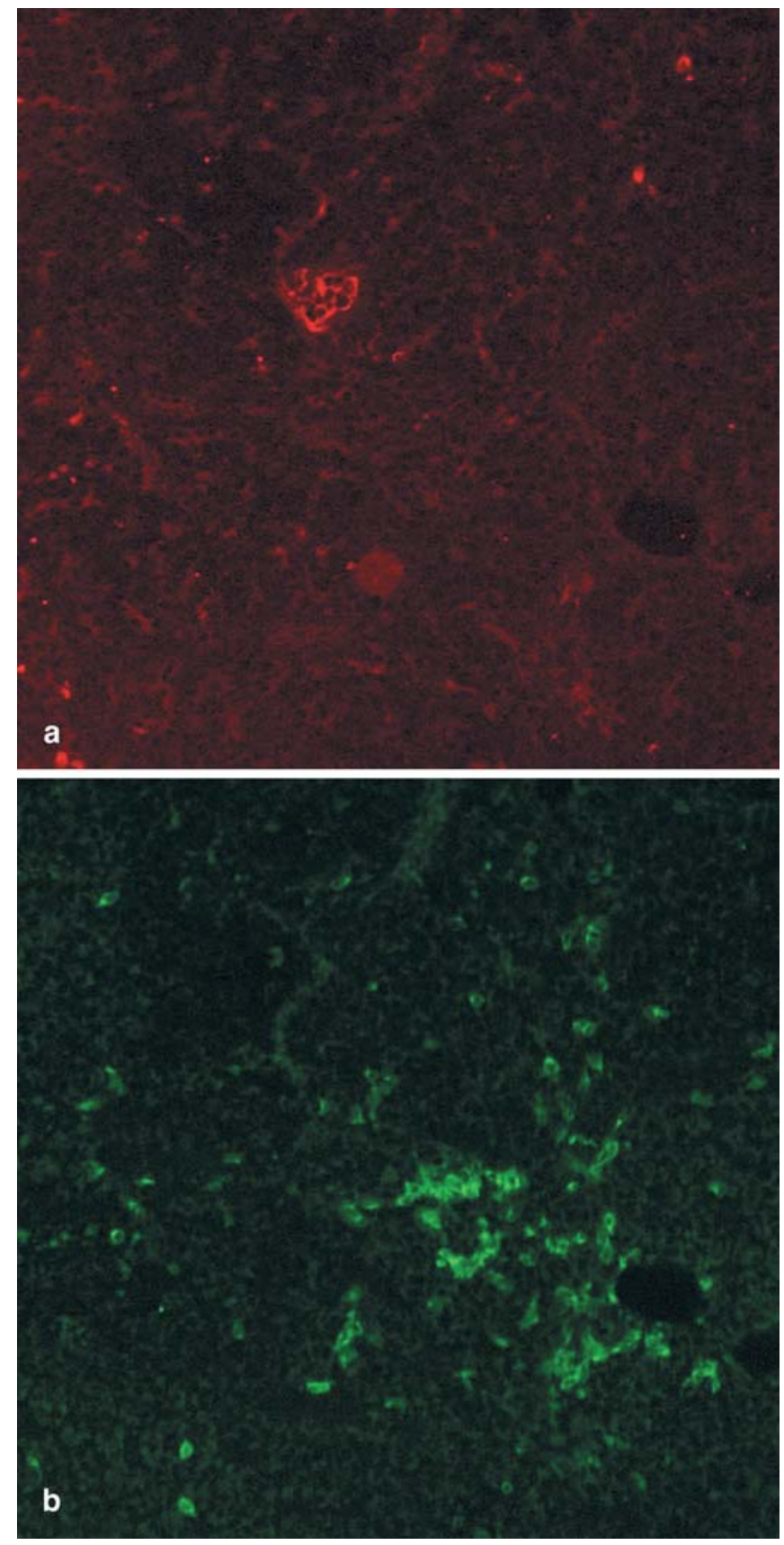

Fig. 1. Photomicrographs of serial section of double-stained pancreatic biopsy specimens. The two panels show pancreatic alpha cells (a) and $\mathrm{CD}^{+}{ }^{+} \mathrm{T}$ cells $(\mathbf{b})$ in a biopsy specimen from one representative patient. $\mathrm{CD} 3^{+} \mathrm{T}$ cells are scattered out of, but not infiltrated into, an islet. This is a typical finding in fulminant Type 1 diabetes. Original magnification: $\times 140$

\section{Results}

Patient characteristics. Characteristics of all patients with fulminant Type 1 diabetes are shown in Table 1. All fulminant Type 1 diabetic patients participating in this study showed rapid onset of diabetes with little insulin secretion (F-CPR $<0.07 \mu \mathrm{mol} / \mathrm{l})$. They also showed no diabetes-related autoantibodies (GAD, IA-2 or ICA), 

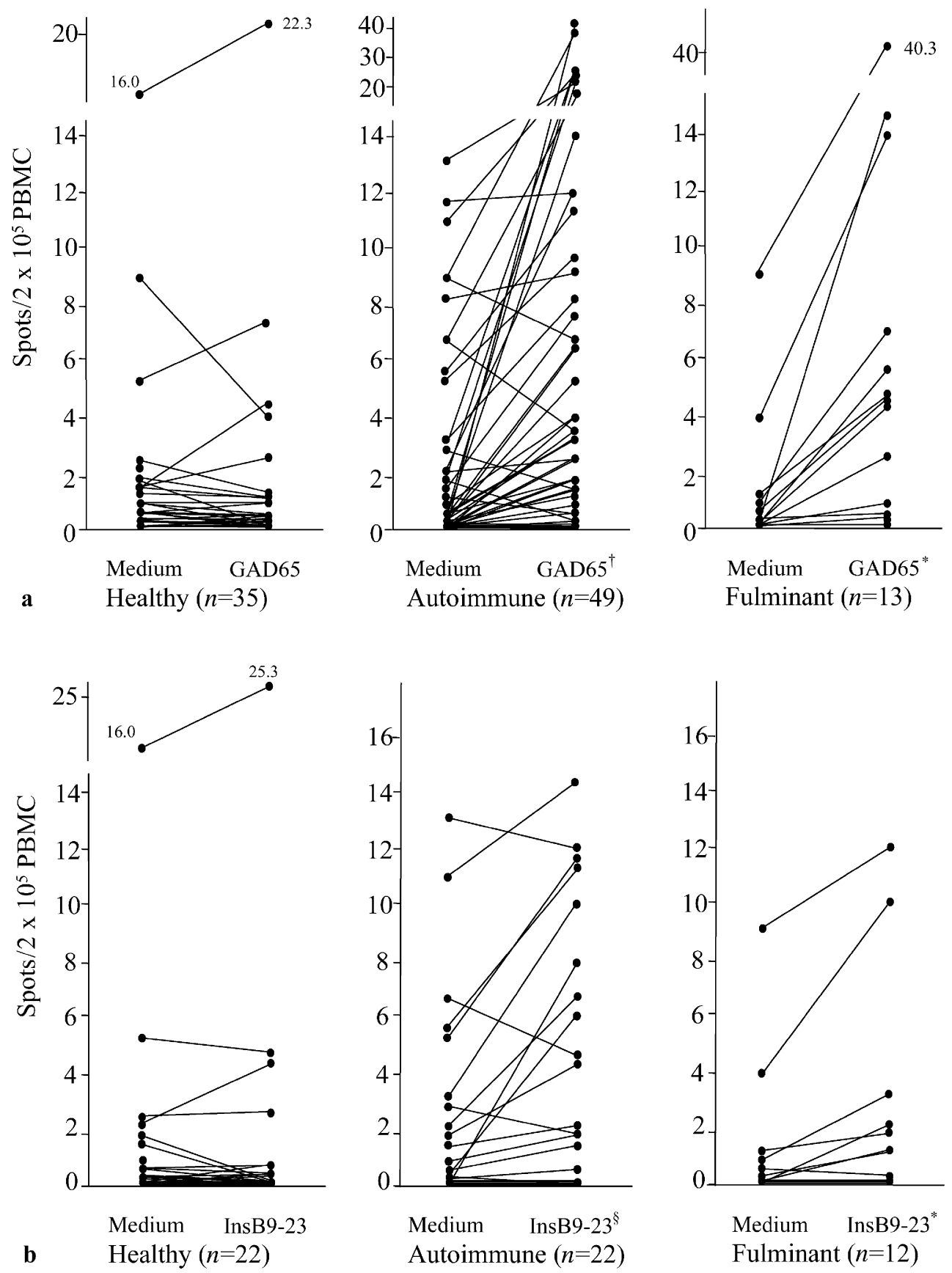

Fig. 2. IFN- $\gamma$ responses to GAD65 (a) and insulin B9-23 peptide (b) in ELISPOT assay. Individual spot formation for GAD65 and insulin B9-23 peptide is shown in healthy controls, in autoimmune Type 1 diabetes subjects and in fulminant Type 1 diabetes subjects. In subjects with autoimmune Type 1 diabetes and in those with fulminant Type 1 diabetes, we recorded significant antigen-stimulated responses when compared with the responses without antigens. ${ }^{\dagger} p<0.0001,{ }^{*} p<0.05,{ }^{\S} p<0.005$ by Wilcoxon matched pair test

and low glycosylated haemoglobin $\left(\mathrm{HbA}_{1} \mathrm{c} \leq 7.6 \%\right)$ at the onset of overt diabetes. The duration of diabetes at the time of the assays ranged from 3 weeks to 11 years. In three of 13 patients, pancreatic biopsy demonstrated T-lymphocyte-predominant infiltration in the exocrine pancreas without insulitis (Fig. 1). There are no histological changes typically observed in acute or chronic pancreatitis, such as oedema, necrosis, fatty degeneration or fibrosis. All of the six pancreatic diabetic patients were treated with insulin, their insulin secretion over the F-CPR range varying from 0.1 to $0.5 \mu \mathrm{mol} / \mathrm{l}$.

Islet cell antigen-reactive T cells in the ELISPOT assay. Significant IFN- $\gamma$ response to GAD65 and insulin B9-23 peptide in the ELISPOT assay were observed in fulminant Type 1 diabetes, as in autoimmune Type 1 diabetes (Fig. 2). In contrast, no significant changes in background were detected in controls.

To compare the positivity among groups in the ELISPOT assay, antigen-stimulated spots were plot- 
ted with subtraction of background (Fig. 3). For the comparison, cut-off values for GAD- and insulinB9-23-stimulated IFN- $\gamma$, as well as for GAD-stimulated IL-4, were determined at the mean +3 SD of the healthy controls $(2.32,1.92$ and 0.35 spots respectively, per $2 \times 10^{5} \mathrm{PBMC}$ ), since most of the healthy controls produced spots with less than the value of the mean $+3 \mathrm{SD}$ of the controls. To exclude the response influenced by the high background, the response that was less than two times lower than the background was considered negative regardless of the cut-off value. With the cut-off value, the GAD-stimulated IFN- $\gamma$ spots were detected in $46.9 \%$ (23/49) of antibody-positive autoimmune Type 1 diabetic patients (Fig. 3a), and insulin B9-23-stimulated IFN- $\gamma$ spots were also observed in $31.8 \%$ (7/22) of those patients (Fig. 3b). IFN- $\gamma$ spots in response to GAD and insulin B9-23 peptide in fulminant Type 1 diabetic patients were detected in $69.2 \%$ and $25 \%$ of patients respectively (Fig. 3). Lower positivity of GAD reactivity in autoimmune Type 1 diabetic patients compared with in fulminant Type 1 diabetic patients might be due to the longer duration after onset (mean $\pm \mathrm{SD}, 7.9 \pm 9.3$ vs $3.1 \pm 4.2$ ). All three insulin-B9-23reactive fulminant Type 1 diabetic patients also showed GAD reactivity. Two of the three fulminant Type 1 diabetic patients without evidence of insulitis by pancreatic biopsy showed GAD-reactive IFN- $\gamma$ spots. Subjects without Type 1 diabetes generated no GAD- and insulin-B9-23-stimulated IFN- $\gamma$ spots, except one healthy control and one Type 2 diabetic patient who showed relatively low insulin secretion (F-CPR; $0.22 \mathrm{nmol} / \mathrm{l})$.

Of the autoantibody-positive autoimmune Type 1 diabetic patients, $10 \%$ (5/49) generated positive GADreactive IL-4 spots, whereas no GAD-reactive IL-4 spots were detected in 12 fulminant Type 1 diabetic patients, as in 40 control subjects (data not shown). IL-4 spots in response to insulin B9-23 were not detected in any group (data not shown).

The ELISPOT assay was performed with control antigens (PHA and PPD). PHA stimulation generated large numbers of IFN- $\gamma$ spots $(>100 /$ well $)$ and IL-4 spots ( $>50 /$ well) in all five groups. Stimulation with PPD resulted in different numbers of IFN- $\gamma$ spots depending on the donor $\left(0\right.$ to $>50$ per $2 \times 10^{5}$
PBMC). No differences in reaction, for both control antigens, were observed among the groups using one-way factorial ANOVA and multiple comparison tests.
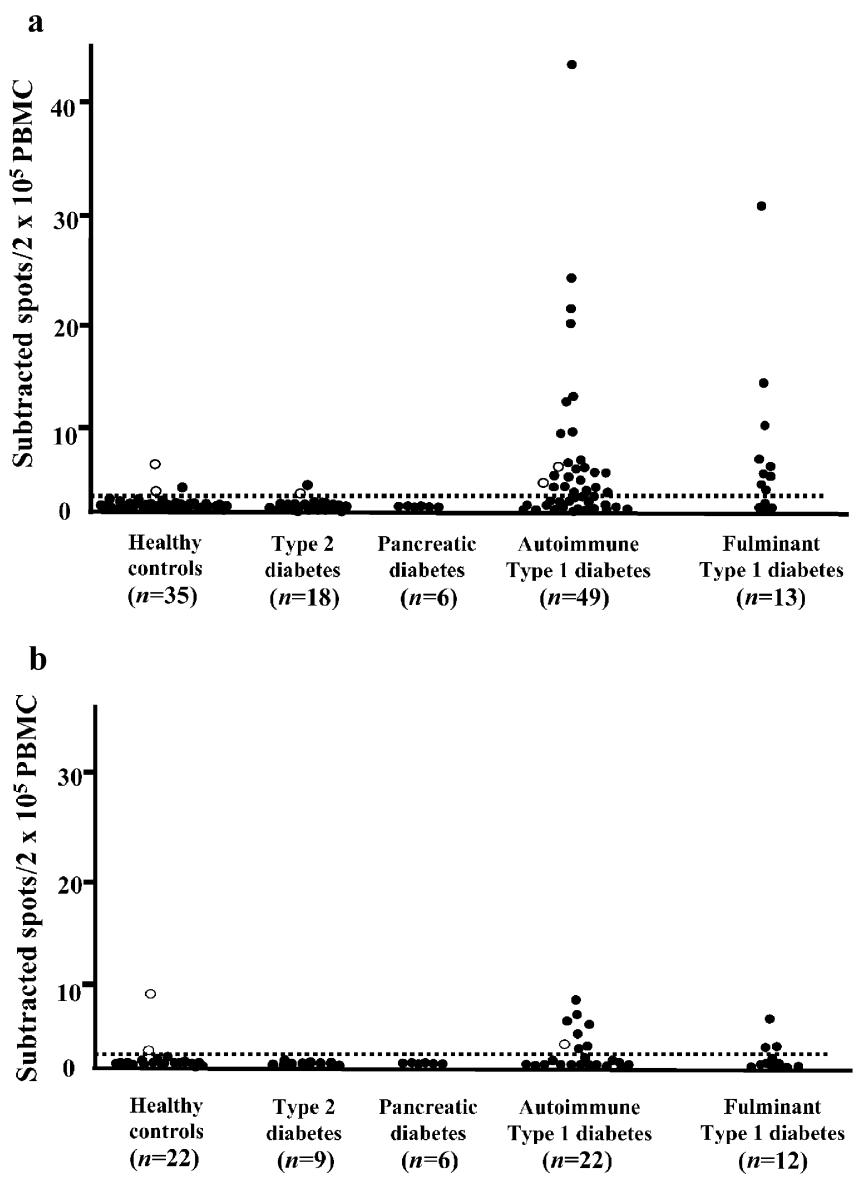

Fig. 3. Comparison of the IFN- $\gamma$ secretion induced by islet autoantigens GAD65 (a) and insulin B9-23 (b). Individual IFN- $\gamma$ spots are depicted as separate dots. The number of antigenstimulated spots was calculated as the mean number of spots obtained with antigen minus the mean obtained without stimulation. Each horizontal line represents the mean + 3SD of the healthy control population (GAD-stimulated spots, 2.32; insulin-B9-23-stimulated spots, 1.92). Open circles show the negative spots that were over the cut-off value as the number of spots was less than two times the background response. Fulminant Type 1 diabetic patients showed significant production of GAD-stimulated and insulin-B9-23-stimulated IFN- $\gamma$ spots when compared with healthy control subjects $(p<0.0005$ and $p<0.05$ respectively, by the Kruskal Wallis test)

Table 2. Correlation between HLA-DR allele and the positivity of GAD-reactive ELISPOT assay

\begin{tabular}{|c|c|c|c|c|c|c|}
\hline & \multirow{2}{*}{$\begin{array}{l}\text { Positivity of } \\
\text { total subjects } \\
\text { a }\end{array}$} & \multirow[t]{2}{*}{$n^{\mathrm{b}}$} & \multirow{2}{*}{$\begin{array}{l}\text { Positivity of patients } \\
\text { with HLA analysis }\end{array}$} & \multicolumn{2}{|c|}{ Susceptible allele } & \multirow{2}{*}{$\frac{\text { Resistant allele }}{\text { DR2a }^{a}}$} \\
\hline & & & & $\mathrm{DR} 4^{\mathrm{a}}$ & DR9a & \\
\hline Fulminant Type 1 diabetes & $9 / 13(69.2 \%)$ & 12 & $8 / 12(66.7 \%)$ & $7 / 11(63.6 \%)$ & $0 / 1(0 \%)$ & $3 / 4(75 \%)$ \\
\hline Pancreatic diabetes & $0 / 6(0 \%)$ & 5 & $0 / 5(0 \%)$ & $0 / 2(0 \%)$ & $0 / 3(0 \%)$ & $0 / 1(0 \%)$ \\
\hline
\end{tabular}

a Number of patients with GAD-reactive IFN- $\gamma$ spots/number of total or HLA-positive subjects; ${ }^{b}$ number of patients with HLA analysis 
HLA class II typing and islet cell antigen reactivity in $P B M C$. All autoantibody-positive autoimmune Type 1 diabetic subjects $(n=14)$ expressed an allele susceptible to Type 1 diabetes, namely DR4 or DR9, without the resistant allele DR2 [16] (Table 2). Of HLA-examined autoantibody-positive autoimmune Type 1 diabetic patients, $45 \%$ showed GAD-reactive spots, while four pancreatic diabetic patients with DR4 and/or DR9 did not show GAD-reactive spots. DR4 was also found in 11 out of 12 fulminant Type 1 diabetic patients. In contrast to in autoantibody-positive autoimmune Type 1 diabetic subjects, resistant allele DR2 was unexpectedly found in four out of 12 fulminant Type 1 diabetic patients (Table 1). Among these four patients, three were heterozygous for DR2/DR4, and one was heterozygous for DR2/DR6, without any diabetes-susceptible alleles. Interestingly, GAD-reactive, IFN- $\gamma$-producing cells were observed in three of the four patients (two with DR2/DR4 and one with DR2/DR6).

\section{Discussion}

In the previous report, there was no evidence of autoimmunity in fulminant Type 1 diabetes as characterised by diabetes-related antibodies and or by pancreatic histology. In the present study, islet cell antigen-reactive Th1 cells were detected in the PBMC of over two-thirds of fulminant Type 1 diabetic patients. Islet cell antigen-reactive Th1 cells were observed in two out of three patients with cellular infiltration of pancreatic acinar tissue but not of islets. In contrast, no anti-islet cell immunity was detected in patients with pancreatic diabetes even with diabetes-susceptible alleles. Therefore, it is unlikely that the secondary beta cell destruction due to the T cell infiltration in the acinar tissue can lead to the detection of peripheral immune reaction to GAD or insulin by ELISPOT assay.

It has been proposed that the development of Type 1 diabetes is controlled by autoreactive $\mathrm{T}$ cells of the Th1 arm which is primarily associated with cellular immunity, rather than of the Th2 arm which is mainly involved in humoral immunity and immunoregulatory suppression $[17,18,19]$. In our study, no GAD-reactive, IL-4-secreting T cells were detectable in fulminant Type 1 diabetic patients, whereas $10 \%$ of autoantibody-positive Type 1 diabetic subjects showed IL-4 spots. A powerful Th1 shift of the immune response with a loss of regulatory cells might allow rapid beta cell destruction by strong cellular immunity, which was detected by ELISPOT assay without detecting autoantibodies to islet antigens [20, 21, 22].

In HLA typing, most fulminant Type 1 diabetic patients have the diabetes-susceptible allele DR4, suggesting that the same HLA allele as in classical autoimmune Type 1 diabetes also contributes to the devel- opment of fulminant Type 1 diabetes. When compared with susceptible haplotypes, resistant HLA haplotype DR2 has a strong protective effect on the development of classical autoimmune Type 1 diabetes, so subjects with the diabetes-resistant haplotype rarely develop diabetes [23]. In the present study, diabetes-resistant alleles were frequently found in fulminant Type 1 diabetic patients $(36.4 \%)$. In addition, three out of four DR2-positive fulminant Type 1 diabetic patients showed positive GAD-reactive IFN- $\gamma$ spots. These results suggest that strong environmental factors might be involved in the development of Type 1 diabetes, overriding the influence of genes protecting against the disease.

Viral infections have the potential to induce proinflammatory responses, with activation of lymphocytes and professional antigen-presenting cells which are eventually crucial for the adoptive immune response to beta cells. Viral infections may be one of the initial factors in the pathogenesis of fulminant Type 1 diabetes. Flu-like symptoms suggesting the pre-existence of a viral infection were observed in $71.7 \%$ of fulminant diabetic patients, in contrast to in only $26.9 \%$ of Type 1A diabetic patients [5]. Cases of human herpesvirus 6 [8] and Echovirus [9] were reported to precede infection before the onset of fulminant Type 1 diabetes.

In a rodent model, it has been suggested that viruses are involved in the pathogenesis of Type 1 diabetes in at least two distinct ways: (i) by inducing beta-cellspecific autoimmunity; and (ii) by inducing cytolytic infection leading to the destruction of the beta cells [24]. The infection of genetically susceptible strains of mice with a high titre of EMC-D (D variant of the encephalomyocarditis) results in the rapid onset of diabetes within 3 days, largely due to the replication of the virus within beta cells. No evidence has yet been found to suggest a direct cytolytic effect of the virus on human beta cells of Type 1 diabetes. However, it is possible that a similar pathogenesis may be involved in cases of human fulminant diabetes.

Similarly, in the study of fulminant myocarditis, viral persistence and autoimmune mechanisms were extensively investigated in the pathogenesis of the disease, using human samples and animal models [25, 26]. It is still unknown whether the major cause of myocarditis is direct myocardial damage from the virus or immune-mediated myocardial impairment, but it has been speculated that both mechanisms could be involved in the pathogenesis.

In conclusion, islet cell antigen-reactive $T$ cells in the peripheral blood were detected in patients with a novel subtype of Type 1B diabetes characterised by a rapid onset and the absence of diabetes-related autoantibodies. This finding is the first evidence of an immune-mediated reaction in fulminant Type 1 diabetes and may help to elucidate the mechanisms involved in Type 1B diabetes, especially in fulminant 
Type 1 diabetes. As some studies suggest that Type 1 diabetic patients are "hyperreactive", the lack of control antigens may be a limitation of this study. Appropriate numbers of control antigens would be required in further studies. More detailed characterisation of the roles of autoreactive $\mathrm{T}$ cells by ELISPOT assay (e.g. CD4 vs CD8, time course of $\mathrm{T}$ cell reaction) would also be important. Further investigation is necessary to clarify the genetic or environmental factors that may modify the form of onset resulting in autoimmune or idiopathic beta cell destruction.

Acknowledgements. This work was partly supported by Insulin Kenkyukai and a grant from the 21st Century COE Program "Center of Excellence for Signal Transduction Disease: Diabetes Mellitus as Model" from the Ministry of Education, Culture, Sports, Science and Technology of Japan. We are highly grateful to Dr George Eisenbarth and Dr Edwin Liu for providing the insulin B9-23 peptide and for suggesting we produce this manuscript.

\section{References}

1. Alberti KG, Zimmet PZ (1998) Definition, diagnosis and classification of diabetes mellitus and its complications. Part 1: diagnosis and classification of diabetes mellitus provisional report of a WHO consultation. Diabet Med 15:539-553

2. Expert Committee on the Diagnosis and Classification of Diabetes Mellitus (2003) Report of the expert committee on the diagnosis and classification of diabetes mellitus. Diabetes Care 26 [Suppl 1]:S5-S20

3. Imagawa A, Hanafusa T, Miyagawa J, Matsuzawa Y (2000) A novel subtype of Type 1 diabetes mellitus characterized by a rapid onset and an absence of diabetes-related antibodies. Osaka IDDM Study Group. N Engl J Med 342:301-307

4. Imagawa A, Hanafusa T, Miyagawa J, Matsuzawa Y (2000) A proposal of three distinct subtypes of type 1 diabetes mellitus based on clinical and pathological evidence. Ann Med 32:539-543

5. Imagawa A, Hanafusa T, Uchigata Y et al. (2003) Fulminant type 1 diabetes - a nationwide survey in Japan. Diabetes Care 26:2345-2352

6. Tanaka S, Kobayashi T, Momotsu T (2000) A novel subtype of type 1 diabetes mellitus (correspondence) letter 002. New Engl J Med 342:1835-1837

7. Shimada A, Oikawa Y, Shigihara T, Senda T, Kodama K (2002) A case of fulminant type 1 diabetes with strong evidence of autoimmunity. Diabetes Care 25:1482-1483

8. Sekine N, Motokura T, Oki T et al. (2000) Rapid loss of insulin secretion in a patient with fulminant type 1 diabetes mellitus and carbamazepine hypersensitivity syndrome. JAMA 285:1153-1154

9. Vreugdenhil GR, Schloot NC, Hoorens A et al. (2000) Acute onset of type I diabetes mellitus after severe echovirus 9 infection: putative pathogenic pathways. Clin Infect Dis 31:1025-1031
10. Kotani R, Nagata M, Moriyama H et al. (2002) Detection of GAD65-reactive T-cells in Type 1 diabetes by immunoglobulin-free ELISPOT assays. Diabetes Care 25:13901397

11. Masuda M, Powell M, Chen S et al. (2000) Autoantibodies to IA-2 in insulin-dependent diabetes measurement with a new immunoprecipitation assay. Clin Chim Acta 291:5366

12. Bottazzo GF, Gleichmann H (1986) Immunology and Diabetes Workshops: reports of the first international workshop on the standardization of cytoplasmic islet cell antibodies. Diabetologia 29:125-126

13. Powell M, Prentice L, Asawa T et al. (1996) Glutamic acid decarboxylase autoantibody assay using ${ }^{125}$ I-labelled recombinant GAD65 produced in yeast. Clin Chim Acta 256:175-188

14. Hayakawa N, Premawardhana LD, Powell M et al. (2002) Isolation and characterization of human monoclonal antibodies to glutamic acid decarboxylase. Autoimmunity 35:343-355

15. Imagawa A, Hanafusa T, Tamura S et al. (2001) Pancreatic biopsy as a procedure for detecting in situ autoimmune phenomena in type 1 diabetes: close correlation between serological markers and histological evidence of cellular autoimmunity. Diabetes 50:1269-1273

16. Kawabata Y, Ikegami H, Kawaguchi Y et al. (2002) Asianspecific HLA haplotypes reveal heterogeneity of the contribution of HLA-DR and -DQ haplotypes to susceptibility to type 1 diabetes. Diabetes 51:545-551

17. Radu DL (2001) Cellular mechanisms involved in experimental insulin-dependent diabetes mellitus. Roum Arch Microbiol Immunol 60:203-226

18. Durinovic-Bello I, Hummel M, Ziegler AG (1996) Cellular immune response to diverse islet cell antigens in IDDM. Diabetes 45:795-800

19. Katz DJ, Benoist C, Mathis D (1995) T helper cell subsets in insulin-dependent diabetes. Science 268:1185-1188

20. Harrison LC, Honeyman MC, Deaizpurua HJ et al. (1993) Inverse relation between humoral and cellular immunity to glutamic acid decarboxylase in subjects at risk of insulindependent diabetes. Lancet 341:1365-1369

21. Trembleau S, Penna G, Bosi E, Mortara A, Gately MK, Adorini L (1995) Interleukin 12 administration induces $T$ helper type 1 cells and accelerates autoimmune diabetes in NOD mice. J Exp Med 181:817-821

22. Bosi E, Minelli R, Bazzigaluppi E, Salvi M (2000) Fulminant autoimmune Type 1 diabetes during interferon-alpha therapy: a case of Th1-mediated disease? Diabet Med 18:329-332

23. Ikegami H, Ogihara T (1996) Genetics of insulin-dependent diabetes mellitus. Endocrine J 43:605-613

24. Jun HS, Yoon JW (2001) The role of viruses in type 1 diabetes: two distinct cellular and molecular pathogenetic mechanisms of virus-induced diabetes in animals. Diabetologia 44:271-285

25. Kitaura Y (1981) Experimental coxackie B virus myocarditi in mice. 18 month histopathological and virological study. Jpn Circ J 45:747-762

26. Nakamura H, Yamamura T, Umemoto S et al. (1996) Autoimmune response in chronic ongoing myocarditis demonstrated by heterotopic cardiac transplantation in mice. Circulation 94:3348-3354 